\title{
Local transfer of substances between the blood vessels at the base of the brain
}

\author{
J. Skipor ${ }^{1,3}$ and N. Einer-Jensen ${ }^{2}$ \\ ${ }^{1}$ Institute of Animal Reproduction and Food Research, \\ Polish Academy of Sciences \\ Tuwima 10, 10-747 Olsztyn, Poland \\ ${ }^{2}$ Physiology and Pharmacology, IMB, University of Southern Denmark \\ 5230 Odense M, Denmark
}

(Received 1 June 2006; revised version 7 September 2006; accepted 6 November 2006)

\begin{abstract}
Studies performed on a variety of species (pigs, sheep, rabbits, rats) indicate the existence of a local transfer system of substances between blood vessels located at the base of the cranium (the cavernous sinus - carotid artery vascular complex). This local transfer allows for some hormones synthesized in the brain and hypophysis, as well as biologically active substances absorbed from the nasal mucosa, and drained to the cavernous sinus to reach the brain vasculature in a concentration locally higher than that measured in systemic circulation. The present paper gives an overview of: 1. the major anatomical structure engaged in the transfer, 2. experimental evidence for substance transfer in the vascular complex, 3. factors affecting the transfer and 4. possible physiological importance.
\end{abstract}

KEY WORDS: carotid rete, cavernous sinus, local transfer, nasal administration, pheromones

\section{INTRODUCTION}

Regulation of the body functions is based on nervous signals and humoral messages. By tradition, the humoral signals are divided into cell-to-cell interaction (autocrine, paracrine), and hormones distributed by the circulatory system to the whole organism (endocrine). The "effective" level of a hormone in potential target cells depends on the balance between its uptake and removal. Changes in hormone concentration in the blood supplying the tissue are the main determinants of the

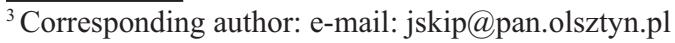


hormones uptake. Some organs have a specific redistribution of hormones via the vascular system that allows for delivery of hormones to the target organs in a concentration higher than that measured in general circulation. This local redistribution is based on the morphological and functional adjustments of circulation in some areas, that allow for the transfer of substances from the venous blood and lymph to the arterial blood through the walls of the closely connected vessels. Physiologically, the transfer facilitates local feedback regulation of organ function in a process situated between general distribution of hormones through the general circulation and paracrine regulation. If the transfer takes place between the major in- and outflow of blood to an organ, the feedback will involve the entire organ and eventually, other organs supplied from the same artery, while if it concerns small organ blood vessels, the regulation will concern only those parts. So far, local transfer of substances between blood and lymph vessels as well as it importance in regulatory mechanisms was well documented for the area of the female and male genital tract (Krzymowski et al., 1990; Stefańczyk-Krzymowska and Krzymowski, 2002; Einer-Jensen and Hunter, 2005).

Krzymowski et al. (1992) discovered that the transfer of substances also take place between venous and arterial vessels located at the base of the brain - in the cavernous sinus (receiving an outflow from the pituitary and a part of the brain) - carotid artery/carotid rete (main vessels supplying the brain and hypophysis) vascular complex.

The present article attempts to describe experimental data concerning the evidence for local transfer of substances between the venous blood from the brain and nasal cavities to the brain arterial blood.

\section{THE CAVERNOUS SINUS - CAROTID ARTERY/CAROTID RETE COMPLEX}

Various authors have comprehensively described the structure and function of the vascular complex of cavernous sinus and carotid rete (Daniel et al., 1953; Godynicki et al., 1981; Ghoshal and Khamas, 1985; Simoens et al., 1987). Therefore, only information relevant to the understanding of the morphological and physiological factors affecting the transfer will be provided in the review.

\section{The cavernous sinuses}

The cavernous sinuses are paired venous channels in the dura located bilaterally on the cerebral surface of the basisphenoid bone, on both sides of the sella and pituitary gland. They are converted into complex neurovascular structures by the 
numerous arteries and cranial nerves contained within their walls, and by their many venous connections. The right and the left cavernous sinus flank the corresponding aspects of the pituitary and are connected to each other by intercavernous sinuses (Figure 1). The venous channels converge around the carotid artery and its branches on several sites to form larger venous spaces, which might be termed "caverns".

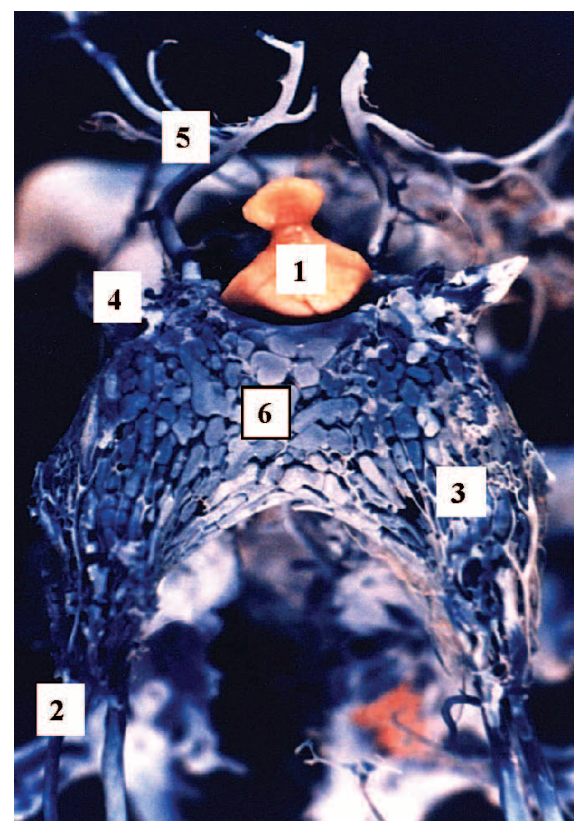

Figure 1. Corrosion cast of the cavernous sinus and rete mirabile epidurale in pigs. Pituitary gland - 1, ascending pharyngeal artery -2 , carotid rete (thin, white vessels between oval shape blue structures) - 3, internal carotid artery - 4, rostral cerebral artery - 5, cavernous sinus (oval shape structures filled with blue Merkox) - 6. prepared by W. Grzegorzewski and photographed by A. Penkowski

Some of the veins form a mesh and allow blood to flow in multiple directions. The afferents to the cavernous sinus come from the pituitary and base of the brain, but most of them drain extracranial areas. The concentration of hypothalamic and pituitary hormones in blood of the cavernous sinus is high. In horses concentration gradients between the intercavernous sinus and the jugular vein exceed 40-fold for LH, 50-fold for ACTH and even 500-fold for vasopressin (Redekopp et al., 1986). In sheep, the amplitude of LH and FSH pulses measured in the blood collected from the cavernous sinus exceed that measured in blood collected from jugular vein 9 and 1.5 times, respectively (Clarke et al., 2002). Some of the drainage to the cavernous sinus originates from the nasal cavity (Ghoshal and Zguigal, 1986). 


\section{The carotid artery and carotid rete}

The arteries supplying the mammalian brain arise from the circle of Willis giving off branches that run deep into the nervous tissue. In man and other primates as well as in rodents, the circle of Willis is supplied by the paired internal carotid arteries and the vertebral-basilar system (Simoens et al., 1987). The pig, sheep and other animals of the Artiodactyla order possess the carotid rete located in the main blood supply to the circle of Willis (Simoens et al., 1987). The carotid rete is an intracranial arterial plexus that consists of a large number of short, thin, and parallel arteries that merge into one vessel before leaving the cavernous sinus. The rete arteries have a well developed elastic lamina, and a tunica media consisting of three to five (goat and pig) or six to eight (cattle) smooth muscle layers (Santamaria et al., 1987). The adventitia is rich in collagen and covered by a single layer of endothelium which forms the lining of the cavernous sinus. This construction creates a huge area with a small diffusion distance between arterial and venous blood that offers the possibility of heat exchange and substance transfer.

\section{EXPERIMENTAL EVIDENCE FOR SUBSTANCE TRANSFER IN THE VASCU- LAR COMPLEX}

Many substances representing several chemical groups (Table 1) were studied in two groups of animals: those with a well developed carotid rete (pigs, sheep)

Table 1. Studies of transfer of biologically active substances from venous blood of the cavernous sinus to arterial blood supplying the brain

\begin{tabular}{llcl}
\hline $\begin{array}{l}\text { Investigated } \\
\text { substance }\end{array}$ & Species & Transfer & References \\
\hline Water & Rats $^{\mathrm{a}}$ & Y & Einer-Jensen and Larsen, 2000b \\
Propanol & Rats $^{\mathrm{a}}$ & Y & Einer-Jensen and Larsen, 2000b \\
Tyrosine & Rats $^{\mathrm{a}}$ & Y & Einer-Jensen and Larsen, 2000b \\
Dopamine & Sheep & Y & Skipor et al., 2001, 2004b \\
Progesterone & Pig, sheep & Y & Krzymowski et al., 1992; Skipor et al., 2003 \\
& Rats & Y & \\
Testosterone & Pig & Y & Skipor et al., 2000 \\
Androstenol & Pig & Y & Krzymowski et al., 1999, 2001; \\
& & & Stefańczyk-Krzymowska et al., 2000 \\
Oxytocin & Pig & Y & Grzegorzewski et al., 1995 \\
$\begin{array}{l}\text {-endorphin } \\
\text { LHRH }\end{array}$ & Sheep & Y & Krzymowski et al., 1992; Skipor et al., 1997 \\
& Pig, Sheep & Y & Krzymowski et al., 1992; Grzegorzewski et al., \\
Prolactin & Sheep & & 1997; Skipor et al., 1999 \\
LH & Sheep & N & Skipor et al., 2004a \\
Diazepam & Rats $^{\mathrm{a}}$ & N & Skipor et al., 2004a \\
Cocaine & Rats $^{\mathrm{a}}$ & Y & Einer-Jensen and Larsen, 2000a \\
Sumatriptan & Rats $^{\mathrm{a}}$ & N & Einer-Jensen and Larsen, 2000a \\
Naratriptan & Rats $^{\mathrm{a}}$ & N & Einer-Jensen et al., 2001 \\
a - male rats & & N & Einer-Jensen et al., 2001 \\
\hline
\end{tabular}


and those without carotid rete (rats, rabbits). Most of the experiments in pigs and sheep have been performed on a model of the perfused isolated head (Krzymowski et al., 1992). The advantage of this model is the absence of recirculation through the general circulation. The head must be considered brain-dead since the circulation was stopped during the preparatory period, but the function of the vessels seemed undisturbed. In vivo model developed for rats (Einer-Jensen and Larsen, 2000a) and pigs (Stefańczyk-Krzymowska et al., 2000) utilizes transfer via venous drainage from the nasal cavity to the cavernous sinus and then to the brain and hypophysis. In anaesthetized rats or pigs parallel blood samples were collected from two catheters inserted into the same carotid artery; the two tips were pointing towards the head and the heart respectively. A head:heart ratio grater than 1.00 indicated that nasally infused substances were transferred locally in the circulatory system to the head.

\section{FACTORS AFFECTING THE TRANSFER}

Information is limited concerning the mechanism of the retrograde transfer of substances between the blood vessels at the base of brain. From the general point of view, transfer of substances between vessels is based on the anatomical structures, flow rates, and the physico-chemical properties of the substances.

\section{Molecular size}

According to previously published data (Grzegorzewski et al., 1995, 1997; Skipor et al., 1997, 2000, 2001, 2003, 2004a) we present calculations indicating that the passage of molecules through the walls of the cavernous sinus - carotid rete complex depends on the size of molecules (Figure 2). A sharp upper limit for the

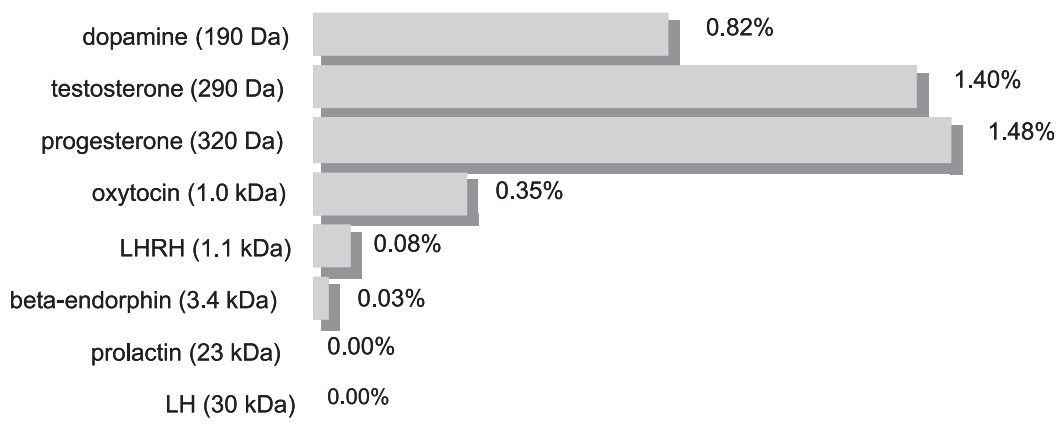

Figure 2. Estimated level of the transfer for labelled molecules with different molecular mass, presented as percentage of total infused dose. All molecules were infused into the cavernous sinus in the similar dose of $7.35 \times 10^{7} \mathrm{dpm}$ for tritium labelled and $6.65 \times 10^{7} \mathrm{dpm}$ for iodine labelled. Calculated on the base of the mean level of radioactivity in arterial blood and blood volume collected during 12 min of experiment 
molecular size has not been established, but substances with a large molecular weight such as prolactin and LH are not transferred (Skipor et al., 2004a). Celia and Osol (2005) observed a similar relationship between molecular weight and the passage of substances through the uterine vein. The authors using two different molecular weight fluorescent dextrans, has demonstrated higher permeability of uterine vein to $3-\mathrm{kDa}$ than $70-\mathrm{kDa}$ dextran in both non-pregnant and late pregnant rats. There are two possible mechanisms for the passage of substances across the walls of the carotid rete and cavernous sinus: bulk flow through openings between cells (paracellular transport) and the active shuttling of molecules by transcellular transport. It has been demonstrated that blocking membrane $\mathrm{Na}^{+}, \mathrm{K}^{+}$ATP-ase by ouabain reduced the transfer of $\beta$-endorphin in the perihypophyseal vascular complex in sheep (Skipor et al., 1997).

\section{The oestrous cycle and reproductive activity}

Strong evidence exists for an influence of the female reproductive cycle on the local transfer of neuropeptides and steroids between vessels in pigs and sheep (Krzymowski et al., 1992; Grzegorzewski et al., 1995, 1997; Skipor et al., 1997, 2003). In contrast, studies performed on female rats showed that progesterone transfer between vessels of the cavernous sinus - carotid artery complex in females is not affected by hormonal milieu (Skipor et al., 2003). In pigs, a subsequent comparison of the transfer of ${ }^{125} \mathrm{I}$-oxytocin, ${ }^{125} \mathrm{I}$-LHRH and ${ }^{3} \mathrm{H}$-progesterone during different days of the oestrous cycle showed that both labelled neuropeptides transferred only on Days 1-3 and 12-14 of the oestrous cycle, while progesterone

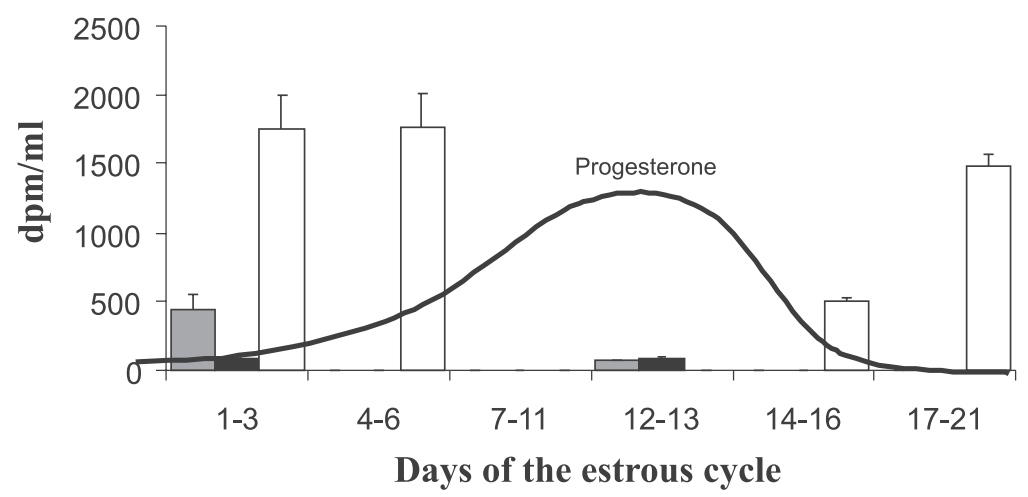

Figure 3. Mean radioactivity values for progesterone (white bars), oxytocin (grey bars), LHRH (black bars) in arterial blood taken from the carotid rete via the carotid artery in gilts on different days of the estrous cycle. Calculated from Grzegorzewski et al., 1995, 1997; Skipor et al., 2003 
transferred on Days 1-6 and 14-21 (Figure 3). The data may indicate that in gilts an efficacy of progesterone transfer is opposite to its endogenous level during the oestrous cycle. However, it should be noted, that ${ }^{3} \mathrm{H}$-progesterone (as well as other labelled molecules) might be considered only a marker of the permeation process and its intensity. Therefore, their mass corresponding to the values of radioactivity estimated in the blood, plasma or tissue samples did not represent the amounts of the hormone (endogenous and radioactive together) transferred from the venous blood of the cavernous sinus into the arterial blood supplying the brain and hypophysis. A reverse trend in the intensity of the steroid transfer comparing to their endogenous level may reflect therefore a competition between the endogenous cold steroids and the labelled steroids infused into the cavernous sinus.

It has been documented that in sheep the endocrine stage of the ewe also affected transfer of ${ }^{3} \mathrm{H}$-dopamine. However, the effect of oestradiol treatment on the intensity of ${ }^{3} \mathrm{H}$-dopamine transfer was observed only during anoestrus (Skipor et al., 2001). Therefore, the trend in the intensity of ${ }^{3} \mathrm{H}$-dopamine transfer seems to be reverse of the dopaminergic tone of the medial basal hypothalamus and median eminence during anoestrus, when dopamine content in median eminence is high. Similar, seasonal variations in the intensity of the transfer were observed also for ${ }^{125}$ I-LHRH and ${ }^{125}$ I- $\beta$-endorphin (Krzymowski et al., 1992; Skipor et al., 1997). Transfer of these neuropeptides was present during reproductive season when during anoestrus was almost neglectible. In seasonally anoestrous sheep, transfer of ${ }^{125}$ I-LHRH was restored after oestradiol benzoate was administered for five days (Krzymowski et al., 1992). On the other hand, in ovariectomized sheep oestradiol benzoate decreases the intensity of ${ }^{125}$ I-LHRH transfer in the time when the endogenous level of LH was high due to the positive action of oestradiol benzoate on LHRH and LH secretion (Skipor et al., 1999). Moreover, this effect was potentiated by hCG, receptors of which were found in the walls of venous and arterial component of the periovarian vascular complex (Skipor et al., 1999). In ovariectomized gilts a higher intensity of ${ }^{125}$ I-LHRH transfer was observed in animals treated with oestradiol benzoate (during the period of LH decrease) compare with an oil-treated animals (Grzegorzewski et al., 1997). These variations in the effect of oestradiol on the transfer of ${ }^{125}$ I-LHRH could result from the use of ovariectomized vs intact animals and the time between oestradiol benzoate injection and experiment inducing negative vs positive feedback for $\mathrm{LH}$ secretion. In generally, the mechanism of oestradiol action is not known. It can be assumed that oestradiol affect LHRH transfer efficacy at least in two areas. In the vessels of the perihypophyseal vascular complex, oestradiol may participate in the regulation of vessel permeability, as it was suggested for other vascular beds (Van Buren et al., 1992), and at the hypothalamus and pituitary levels, regulating LHRH 
and LH release and therefore their concentration in the venous blood reaching the cavernous sinus.

\section{THE POSSIBLE PHYSIOLOGICAL IMPORTANCE}

The local transfer of biologically active substances in the perihypophyseal vascular complex raises the possibility that it may serve some physiological function. A humoral pathway for the priming action of male pheromone in female pigs is one very special function. Intraspecies communication by chemical signals (pheromones) plays important behavioural and physiological roles in coordinating reproduction in mammals. Pheromones act by stimulating the dendritic receptors of chemosensory neurones in the olfactory neuroepithelium in the nasal cavity, and in the vomeronasal organ. Such a mechanism seems to be well adapted for transmitting information induced by signalling pheromones, that are responsible for changes in behavioural and sexual activity. It has been demonstrated that in female pigs priming pheromone - androstenol, that set in motion a chain of neuroendocrine and endocrine events may use a local humoral pathway to reach the hypophysis and brain (Krzymowski et al., 1999, 2001; Stefańczyk-Krzymowska et al., 2000). In both ex vivo and in vivo experiments the resorption of ${ }^{3} \mathrm{H}$-androstenol from the respiratory part of the nasal mucosa into the venous blood in the nasal cavity and its subsequent local transfer in the periohypophyseal vascular complex into the arterial blood supplying the brain, as well as its arrest in certain brain structures, were demonstrated. In anaesthetized gilts ${ }^{3} \mathrm{H}$-androstenol was found in the anterior hypothalamus, i.e. at the site of LHRH, oxytocin and vasopressin synthesis, while was not present in the mediobasal hypothalamus where the transport and release of this peptides take place (Stefańczyk-Krzymowska et al., 2000). It was also found that intramuscular injections of androstenol stimulate the development and secretory function of the ovarian follicles in gilts during sexual maturation, during perioestrous period affect the ovarian morphology and influences hormonal regulation in hypoosmatic gilts (Stefańczyk-Krzymowska et al., 2002, 2003, 2005). It has been demonstrated, just recently, that androstenone and androstenol (pig pheromenes) directly affect the reactivity of the superficial veins of the face and nose in the female pigs that may play an important role in the mechanism regulating direction of venous outflow from the nose to the cavernous sinus (Grzegorzewski, 2005, 2006).

Although there is presently no experimental evidence for its participation in another regulatory mechanism it is worth considering that this phenomenon allows for some substances secreted from brain centres, the pituitary gland and the retina to reach the pituitary and other brain centres (if they pass the blood brain barrier) in a concentration higher than that measured in general circulation. The advantage 
of the local transfer is an increase in specific impact since the message is not evenly diluted in the general circulation. It has so far been an overlooked method for distribution of humoral signals from one brain centre to other parts of the brain. In our opinion, it may be regarded as a semispecific intermediate between distribution via the general circulation and paracrine distribution. One brain centre will communicate, through the vascular system, with other centres; an example of this is the ability of LHRH, oxytocin, $\beta$-endorphin (released in neurohypophysis) to reach other brain centres with arterial supply. This has specific, but as yet not fully determined function in the regulation of reproduction or other physiological processes on the brain and pituitary level.

\section{REFERENCES}

Celia G., Osol G., 2005. Uterine venous permeability in the rat is altered in response to pregnancy, vascular endothelial growth factor, and venous constriction. Endothelium - New York 12, 81-88

Clarke I., Moore L., Veldhuis J., 2002. Intensive direct cavernous sinus sampling identifies highfrequency, nearly random patterns of FSH secretion in ovariectomized ewe: combinet appraisal by RIA and bioassay. Endocrinology 143, 117-129

Daniel P.M., Dawes J.D.K., Prichard M.M.L., 1953. Studies of the carotid rete and its associated arteries. Phil. Trans. Roy. Soc., London, B 237, 173-208

Einer-Jensen N., Hunter R.H.F., 2005. Counter-current transfer in reproductive biology. Reproduction $129,9-18$

Einer-Jensen N., Larsen L., 2000a. Local transfer of diazepam, but not of cocaine, from the nasal cavities to the brain arterial blood in rats. Pharmacol. Toxicol. 87, 276-278

Einer-Jensen N., Larsen L., 2000b. Transfer of tritiated water, tyrosine, and propanol from the nasal cavities to the brain arterial blood in rats. Exp. Brain Res. 130, 216-220

Einer-Jensen N., Larsen L., Deprez S., Starns E., Schwartz S., 2001. Intranasal absorption of sumatriptan and naratriptan: no evidence of local transfer from the nasal cavities to the brain arterial blood in male rats. Biopharm. Drug Dispos. 22, 213-219

Ghoshal N.G., Khamas W.A.H., 1985. Gross and histomorphological study on the rostral epidural rete mirabile of the pig. Indian J. Anim. Sci. 55, 304-310

Ghoshal N.G., Zguigal H., 1986. Dural sinuses in the pig and their extracranial venous connections. Amer. J. Vet. Res. 47, 1165-1169

Godynicki S., Schwarz R., Radke B., 1981. Mikromorphologische Untersuchungen am Rete Mirabile epidurale Rostrale und am Sinus Cavernosus des Schafes (Ovis aries). Zbl. Vetmed. C 10, 227-237

Grzegorzewski W.J., 2005. The influence of male pheromones on the contractile reactivity of the isolated superficial veins of the nose and face during the estrous cycle in gilts. Pol. J. Vet. Sci. 8, $57-64$

Grzegorzewski W.J., 2006. The influence of boar pheromones on the contractile reactivity of the isolated superficial veins of the nose and face in ovariectomized prepubertal gilts and in gilts during sexual maturation. Pol. J. Vet. Sci. 9, 127-133

Grzegorzewski W., Skipor J., Wąsowska B., Krzymowski T., 1995. Counter current transfer of oxytocin from the venous blood of the perihypophyseal cavernous sinus to the arterial blood of carotid rete supplying the hypophysis and brain depends on the phase of the estrous cycle in pigs. Biol. Reprod. 52, 39-144 
Grzegorzewski W., Skipor J., Wąsowska B., Krzymowski T., 1997. Countercurrent transfer of ${ }^{125}$ ILHRH in the perihypophyseal cavernous sinus-carotid rete vascular complex, demonstrated on isolated pig heads perfused with autologous blood. Domest. Anim. Endocrinol. 14, 149-160

Krzymowski T., Grzegorzewski W., Stefańczyk-Krzymowska S., Skipor J., Wąsowska B., 1999. Humoral pathway for transfer of the boar pheromone, androstenol, from the nasal mucosa to the brain and hypophysis of gilts. Theriogenology 52, 1225-1240

Krzymowski T., Kotwica J., Stefańczyk-Krzymowska S., 1990. Uterine and ovarian countercurrent pathways in the control of ovarin function in the pig. J. Reprod. Fertil., Suppl. 40, 179-191

Krzymowski T., Skipor J., Grzegorzewski W., 1992. Cavernous sinus and carotid rete of sheep and sows as a possible place for countercurrent exchange of some neuropeptides and steroid hormones. Anim. Reprod. Sci. 29, 225-240

Krzymowski T., Stefańczyk-Krzymowska S., Grzegorzewski W., Skipor J., Wąsowska B., 2001. A possible humoral pathway for the priming action of the male pheromone androstenol on female pigs. In: A. Marchlewska-Koj, J.J. Lepri, D. Müller-Schwarze (Editors). Chemical Signals in Vertebrates 9. Kluwer Academic/Plenum Publishers, New York, pp. 117-123

Redekopp C., Irvine C.H., Donald R.A., Livesey J.H., Sadler W., Nicholls M.G., Alexander S.L., Evans M.J., 1986. Spontaneous and stimulated adrenocorticotropin and vasopressin pulsatile secretion in the pituitary venous effluent of the horse. Endocrinology 118, 1410-1416

Santamaria L., Dieguez G., Garcia-Villalon A.L., Nava Hernandez E., Gomez B., Lluch S., 1987. Histomorphometry and innervation of the rete mirabile and brain vessels of Artiodactyla. In: J. Cervos-Navarra, R. Ferszt (Editors). Stroke and Microcirculation. Raven Press, New York, pp. 181-185

Simoens P., Lauwers H., De Geest J.P., De Schaepdrijver L., 1987. Functional morphology of the cranial retia mirabilia in the domestic mammals. Schweiz. Arch. Tierheilk. 129, 295-307

Skipor J., Bao S., Grzegorzewski W., Wąsowska B., Rao ChV., 1999. The inhibitory effect of hCG on counter current transfer of $\mathrm{GnRH}$ and the presence of $\mathrm{LH} / \mathrm{hCG}$ receptors in the perihypophyseal cavernous sinus - carotid rete vascular complex of ewes. Theriogenology 51, 899-910

Skipor J., Grzegorzewski W., Einer-Jensen N., Wąsowska B., 2003. Local vascular pathway for progesterone transfer to the brain after nasal administration in gilts. Reprod. Biol. 3, 143-159

Skipor J., Grzegorzewski W., Krzymowski T., Einer-Jensen N., 2000. Local transfer of testosterone from the nasal mucosa to the carotid blood and the brain in the pig. Pol. J. Vet. Sci. 3, 19-22

Skipor J., Grzegorzewski W., Wąsowska B., Krzymowski T., 1997. Counter current transfer of $\beta$ endorphin in the perihypophyseal cavernous sinus - carotid rete complex of sheep. Exp. Clin. Endocrinol. Diabetes 105, 308-313

Skipor J., Grzegorzewski W., Wąsowska B., Krzymowski T., 2004a. Luteinizing hormone and prolactin are not retrograde transferred in perihypophyseal vascular complex in ewes. Reprod. Biol. 4, 195-201

Skipor J., Wąsowska B., Grzegorzewski W., Zezula-Szpyra A., Stefańczyk-Krzymowska S., Thiéry J.-C., 2001. Transfer of dopamine by counter current mechanism in ewe changes with endocrine stage. Biog. Amine. 16, 431-445

Skipor J., Wąsowska B., Picard S., Thiery J.-C., 2004b. Access of dopamine to the median eminence and brain throughout local vascular pathways in sheep. Reprod. Biol. 4, 91-106

Stefańczyk-Krzymowska S., Krzymowski T., 2002. Local adjustment of blood and lymph circulation in the hormonal regulation of reproduction in femele pigs - facts, conclusions and suggestions for future research. Reprod. Biol. 2, 115-133

Stefańczyk-Krzymowska S., Krzymowski T., Grzegorzewski W., Wąsowska B., Skipor J., 2000. Humoral pathway for local transfer of the priming pheromone androstenol from the nasal cavity to the brain and hypophysis in anaesthetized gilts. Exp. Physiol. 85, 801-809 
Stefańczyk-Krzymowska S., Krzymowski T., Wąsowska B., Jana B., Słomiński J., 2003. Intramuscular injections of male pheromone $5 \alpha$-androstenol change the secretory ovarian function in gilts during sexual maturation. Reprod. Biol. 3, 241-257

Stefańczyk-Krzymowska S., Wąsowska B., Jana B., 2002. Boar pheromone androstenol may affect the ovarian morphology in cycling gilts by humoral pathway. Folia Histochem. Cytobiol. 40, $155-156$

Stefańczyk-Krzymowska S., Wąsowska B., Skipor J., 2005. The effect of intramuscular injection of boar pheromone $5 \alpha$-androstenol on the hormonal regulation of the estrous cycle in hypoosmatic gilts. Pol. J. Vet. Sci. 8, 85-91

Van Buren G.A., Yang D S., Clark K.E., 1992. Estrogene-induced uterine vasodilatation is antagonized by L-nitroarginine methyl ester, an inhibitor of nitric oxide synthesis. Amer. J. Obstet. Gynecol. 174, 828-833 